\title{
Involvement of Polyamides in Auxin and Agrobacterium rhizogenes - induced Rooting of Fruit Trees in Vitro
}

\author{
Eddo Rugini \\ Universitá degli Studi dells Tuscia, Istituto di Ortofloroarboricoltura, Facoltá di Agraria, \\ Via S. Camillo de Lellis, Viterbo 01100, Italy \\ Additional index words. micropropagation, transformation, olive, apple, almond, pistachio
}

\begin{abstract}
In the olive Olea europaea (L.), the polyamides (PAs), putrescine, spermidine, and spermine, when added exogenously at a concentration of $1 \mathrm{~mm}$ in the in vitro rooting medium, combined with $5 \mu \mathrm{M}$ auxin concentration, promoted early rooting and increased the final rooting percentage and the number of roots per explant. The effect was less evident in olive explants rooted with the basal blanching method; thin-layer chromatography of total endogenous PAs in 'these explants revealed lower levels on day 2 compared with controls, while by day 5 PA concentrations in both had fallen to similar levels. Furthermore, putrescine decreased the $\mathrm{pH}$ of the medium by 0.5 units around the explants. PAs had little effect on apple Malus pumila (Mill.) and no effect on almond Prunus dulcis (Miller) D.A. Webb and pistachio Pistacia vera (L.). There were also some positive effects observed, but only in olive, when rooting was induced by Agrobacterium rhizogenes in auxin-free medium. Few plantlets showed agropine-positive roots.
\end{abstract}

Root formation from microcuttings is a problem in fruit tree and rootstock propagation in vitro. Root induction is often inefficient, unreproducible, and generally time-consuming, particularly in almond (Rugini, 1986a) and olive (Rugini, 1986b). Proper use of growth regulators, suitable environmental conditions and, more recently, the use of A. rhizogenes as "root inducers" (James, 1987; Patena et al., 1987; Rugini, 1986a, 1986b) have contributed to the improvement of protocols aimed at achieving acceptable root production in micropropagated explants in some recalcitrant woody species. The transfer of the rol $\mathrm{B}$ gene of A. rhizogenes, which increases rooting efficiency even in woody plants, as shown by Rugini et al. (1991) in kiwi [Actinidia deliciosa (A. Chev.) C.F. Liang et R. Ferguson var. delicosa] could be of value for difficult-to-root species if transformation efficiency and regeneration capacity of tissues could be increased. However, the promotion of early rooting and increased rooting efficiency remain objectives that still have to be tackled in several woody species.

PAs have been shown to delay senescence by inhibiting ethylene biosynthesis (Altman et al., 1977; Apelbaum et al., 1981; Smith 1982) and to increase cell division (Bagni et al., 1981). In addition, after auxin treatment, the polyamine content of mung beans [Vigna radiata (L.)] has been found to increase considerably before root emergence, and this increase has been shown to be essential for root initiation (Friedman et al., 1985). However, exogenous treatment did not increase rooting percentage in mung bean (Jarvis et al., 1983) or in cherry (Prunus avium L.) (Biondi et al., 1990). Since putrescine has given positive results in preliminary experiments with early root induction in olive (Rugini and Wang, 1986), the effects of PAs on the rooting of almond, apple, and pistachio shoots as well as on some olive cultivars were studied. Further, the total endogenous PA content was also determined in explants during the first 5 days of rooting.

Received for publication 28 Mar. 1991. Accepted for publication 28 Oct. 1991. I acknowledge the support of the Ministry of Agriculture and Forestry "Piano Nazionale di Ricerca: sviluppo di tecnologie avanzate applicate alle piante," and Claudio Taratufolo for technical assistance. The cost of publishing this paper was defrayed in part by the payment of page charges. Under postal regulations, this paper therefore must be hereby marked advertisement solely to indicate this fact.

\section{Materials and Methods}

Experimental plant tissue included olive shoots of cultivars Moraiolo and Dolce Agogia, which have characteristically variable rooting efficiency, apple (Malus pumila Mill. ) of unknown genotype, Fascionello almond, a gamma-ray mutation, and pistachio seedlings. Olive shoots had been maintained for 4 years in vitro (with subculturing every 35 to 40 days) in OM (olive basal medium, plus $18 \mu \mathrm{m}$ zeatin riboside, $3 \%$ sucrose, and $0.7 \%$ agar) (Rugini, 1986b). Apple shoots also had been maintained in culture for 4 years on Linsmaier and Skoog (1965) medium with $4.4 \mu \mathrm{MBAP}$ and $0.5 \mu \mathrm{MIBA}$, according to James and Thurbon (1979). Pistachio and almond had been maintained in culture for 2 years (with subcultures at 30 and 21 days, respectively) on Murashige and Skoog (1962) (MS) medium plus $1.5 \mu \mathrm{M}$ BAP, $0.05 \mu \mathrm{M}$ NAA, $3 \%$ sucrose, and $0.8 \%$ agar (Rugini, 1986a). All cultures were maintained under a 16-h photoperiod at $40 \mu \mathrm{mol} \cdot \mathrm{m}^{-2} \cdot \mathrm{s}^{-1}$ provided by cool-white fluorescent lamps at $24 \pm 1 \mathrm{C}$. Half-strength MS salts and vitamins supplemented with $2 \%$ sucrose, $0.8 \%$ w/v Difco Bactoagar and either 0.5 or $5 \mu \mathrm{M} \mathrm{NAA}$, at $\mathrm{pH} 5.5$ were used as a rooting medium. All media were autoclave for $15 \mathrm{~min}$ at $121 \mathrm{C}$. The polyamides putrescine (Put), spermidine ( $\mathrm{Spd})$, and spermine (Spin) were filter-sterilized and added to the rooting medium at $1 \mathrm{~mm}$ (Rugini and Wang, 1986). Most of the experiments were carried out using diamine putrescine.

One experiment compared the effect of putrescine on rooting by exposing the explants to a $16 \mathrm{~h}$-light photoperiod at 60 $\mu \mathrm{mol} \cdot \mathrm{m}^{-2} \cdot \mathrm{s}{ }^{-1}$ with or without basal blanching (Rugini et al., 1987). The technique consisted of maintaining the basal part of shoots in darkness during the entire period of rooting by blackening the outside of the jars up to 3 to $4 \mathrm{~mm}$ above the medium and by covering it with small black polycarbonate granules.

Experiments with $A$. rhizogenes (strain NCPPB 1855) were carried out using the same basal rooting medium without auxins. In addition, 5-azacytidine at $28 \mu \mathrm{M}$, auxins [1 $1 \mathrm{H}$-indole-3-acetic acid (IAA), indole-3-butyric acid (IBA), 1-naphthalene-acetic acid (NAA), 2,4-dichlorophenoxyacetic acid (2,4-D)], zeatin, and gibberellic acid $\left(\mathrm{GA}_{3}\right)$ at $5 \mu \mathrm{M}$ (Table 3 ) were tested in an attempt to increase bacterium-induced rooting efficiency. Bat-

Abbreviations: PA, polyamides. 
terial inoculation was carried out by making two superficial longitudinal cuts (5 to $7 \mathrm{~mm}$ long) with an infected knife on the basal portion of the explants. This procedure was compared with a bacterial inoculation by puncturing the middle of the explants with a glass needle.

The rooting tests with auxin or with $A$. rhizogenes involved 60 in vitro-grown shoots per treatment, with two to three nodes for olive and five to six for the other species. The explants were placed separately in test tubes $(120 \times 16 \mathrm{~mm})$ containing $5 \mathrm{ml}$ of medium. The cultures were then placed in a growth chamber at $24 \pm 1 \mathrm{C}$ under $40 \mu \mathrm{mol} \cdot \mathrm{m}^{-2} \cdot \mathrm{s}{ }^{-1}$ light intensity, supplied by cool-white fluorescent lamps; the photoperiod was $16 \mathrm{~h}$. Root growth was recorded every 7 to 10 days, according to the experiments and the species examined. At the end of the experiment, the explants were extracted from the test tube and a $\mathrm{pH}$ sensor was placed where the explants had been, to measure the $\mathrm{pH}$ of the medium. The number of roots per explant was also recorded. The roots of 15 randomly chosen explants rooted by A. rhizogenes were analyzed for opines by paper electrophoresis (White et al., 1982). Data were analyzed by the $x^{2}$ test. Plantlets were then transferred to a mixture of 1.5 peat moss : 1.0 perlite : 0.5 polystyrene granules (by volume) in boxes covered with polyethylene film and placed under a $16-\mathrm{h}$ photoperiod at 60 to $70 \mu \mathrm{mol} \cdot \mathrm{m}^{-2} \cdot \mathrm{s}^{-1}$ in a growth room held at $20 \pm 1 \mathrm{C}$. Before being transferred into pots, the plantlets rooted with A. rhizogenes were washed for $24 \mathrm{~h}$ in a shaker that contained vancomycin solution at $200 \mathrm{mg} \cdot \mathrm{liter}^{-1}$.

Polyamine determination. Perchloric acid (PCA) and total polyamine (Put, Spd, and Spin) concentrations were determined by thin layer chromatography (TLC) (Torregiani et al., 1990) in chloroform : ethylacetate $(4: 2)$ from a $500-\mathrm{mg}$ fresh weight sample. The shoots used for total PA determination were first divided into apical and basal parts, then cultured in rooting medium under the same environmental conditions as those used for the rooting test, with or without (control) basal blanching. The analyses were carried out at 2 and 5 days after the beginning of rooting, a crucial period for the root induction phase, by homogenizing duplicate samples of the whole explants.

\section{Results}

Olive. Both cultivars, Moraiolo and Dolce Agogia, gave similar rooting responses under auxin and PA treatments. PAs affected rooting only in combination with auxin treatment, increasing rooting percentage and promoting earlier root emergence compared with the explants placed on medium with auxin only; Put seemed to be a more active PA than the other two (Fig. 1). Further, Put + NAA also increased the number of roots per explant (Table 1). In auxin-free medium, with or without PAs, not more than $8 \%$ of the explants had rooted (data not shown). The aim of the experiment was to examine the effect of Put at two auxin concentrations. There was a higher percentage of rooted explants in medium containing $5 \mu \mathrm{M}$ NAA than in medium containing $0.5 \mu \mathrm{M}$ NAA, but when $1 \mathrm{~mm}$ Put was added to the media there was no difference in the final rooting percentage (Fig. 2), although the explants in the medium with lower auxin concentration rooted more slowly. At the lower auxin concentration, with or without Put, explants rooted without any basal callus formation, contrary to those placed in $5 \mu \mathrm{M}$ NAA, which formed a large basal callus; the addition of Put promoted further growth (data not shown). When rooting was carried out with basal blanching, Put was not as effective as in the blanched explants, since this method dramatically increased the rooting percentage (Fig. 3).

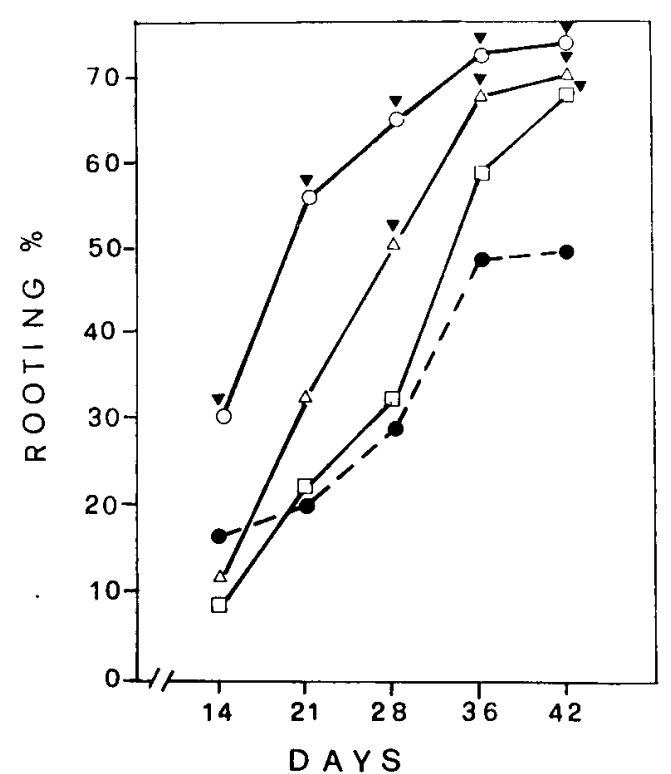

Fig. 1. Effect of $1 \mathrm{~mm}$ polyamines [putrescine (Put), spermidine (Spd), and spermine $(\mathrm{Spm})]$ on rooting of 'Moraiolo' olive explants on medium containing $5 \mu \mathrm{M}$ NAA. Triangles indicate the difference by $\chi^{2}$ test of homogeneity at $P=0.05$ with the corresponding control mean. Put $(O-O)$; Spd $(\triangle-\triangle)$; Spm $(\square-\square)$; Control (- - -). In auxin-free medium, rooting was absent or minimal. Each datum is the mean of 60 explants.

Table 1. Root formation per explant 'Moraiolo' olive after 42 days on half-strength MS rooting medium with various supplements. NAA and putrescine (Put) were added to the medium at $5 \mu \mathrm{M}$ and $1 \mathrm{~mm}$, respectively.

\begin{tabular}{|c|c|c|c|c|c|}
\hline \multirow{2}{*}{$\begin{array}{l}\text { Medium } \\
\text { supplement }\end{array}$} & \multicolumn{5}{|c|}{ No. explants with no. roots indicated } \\
\hline & 0 & 1 & 2 & $3+$ & Total \\
\hline None & 55 & 4 & 1 & $0 \mathrm{a}^{2}$ & 60 \\
\hline Put & 51 & 3 & 4 & $1 \mathrm{a}$ & 59 \\
\hline NAA & 33 & 11 & 12 & $4 \mathrm{~b}$ & 60 \\
\hline $\mathrm{NAA}+$ Put & 11 & 8 & 18 & $22 \mathrm{c}$ & 59 \\
\hline
\end{tabular}

${ }^{2}$ Distribution between lines separated by $x^{2}$ test of homogeneity, $P=$ 0.01 .

Total endogenous PAs were present at a lower concentration in shoots derived from the basal blanching method than the control at 2 days. By 5 days all PAs had decreased in concentration, and it was the same in the explants from the two rooting methods (Table 2).

At the end of the experiment, the medium containing $5 \mu \mathrm{M}$ NAA had a pH of $4.9 \pm 0.06 \mathrm{SD}$, whereas in that containing NAA and Put, the pH was significantly lower $(4.4 \pm 0.08 \mathrm{SD})$ around the basal portion of the explants. The variation was similar in media containing rooted and that containing unrooted explants.

Treatment with A. rhizogenes alone promoted rooting in 26 out of 58 treated explants. An auxin concentration of $5 \mu \mathrm{M}$ in the medium did not increase the rooting percentage when rooting was induced by the bacteria; 2,4-D inhibited rooting and promoted a large basal callus. Zeatin and $\mathrm{GA}_{3}$ at the same auxin concentration decreased rooting drastically (Table 3); 5-azacytidine at $28 \mu \mathrm{m}$ delayed only the early stage of root initiation . (data not shown). Putrescine promoted early rooting and increased the final rooting percentage (Fig. 4, Table 3), as already observed in explants rooted by auxin. The roots emerged from 


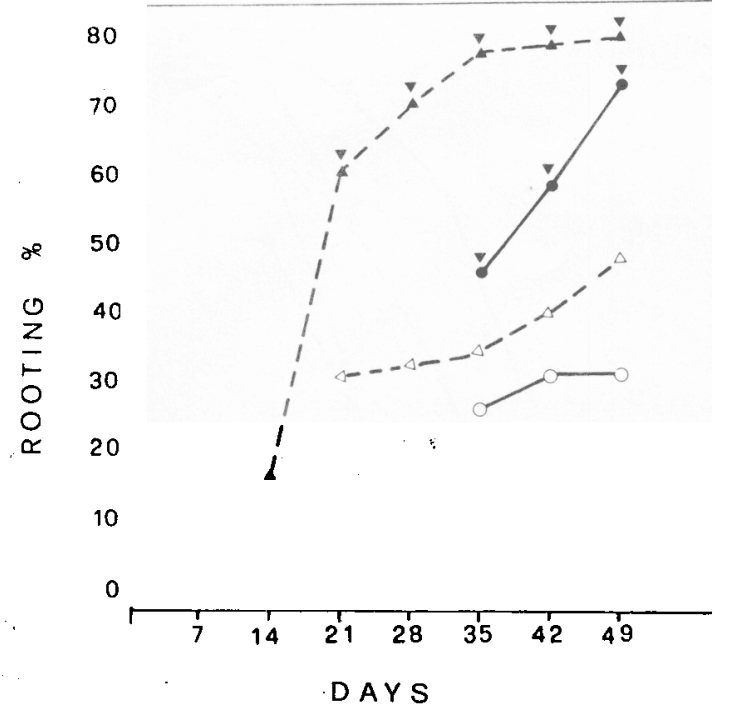

Fig. 2. Effect of $1 \mathrm{mM}$ putrescine and NAA concentration on rooting of 'Dolce Agogia' explants. Triangles placed on each point indicate the difference by $\chi^{2}$ test of homogeneity at $P=0.05$ with the corresponding NAA concentration; at 49 days there was no difference in rooting percentage between 0.5 and $5 \mu \mathrm{M}$ NAA in combination with putrescine. Rooting was absent without auxin. NAA at $0.5 \cdot \mu \mathrm{M}(\mathrm{O}-\mathrm{O}),+$ putrescine $(-0)$; NAA at $5 \mu \mathrm{M}(\Delta--\triangle)$, + putrescine $\left(\Lambda_{-}\right)$; control (--0). Each datum is the mean of 60 explants.

the basal portion of explants in most cases even when inoculation was done with a glass needle in the middle of the explant. Rooting efficiency was similar between the two inoculation methods tested.

Other species. In almond and pistachio, putrescine had no effect on rooting, in apple it had a minimal effect, since it promoted slightly earlier rooting and increased the rooting percentage when compared with shoots rooted with auxin alone (data not shown). When explants were transformed with A. rhizogenes, putrescine increased. bacterial growth around the explants, particularly in almond and pistachio, but not in apple and olive. In all these species, as in olive, Put clearly increased basal callus formation (data not shown). Also, the roots in most cases emerged at the base of the explant, as observed in olive. In all species, only $20 \%$ of the plantlets that rooted with $A$. rhizogenes showed agropine-positive roots, including those grown in medium containing the hypomethylant drug 5-azacytidine.

Plant survival in pots was usually high, $\approx 90 \%$.In some potted olive and almond plantlets, observed after 6 months in pots, the root system induced by $A$. rhizogenes clearly had more secondary roots than shoots rooted with auxins. However, the root systems were similar after 2 years in pots.

\section{Discussion and Conclusion}

The present work shows that polyamides promote early rooting and increase rooting percentage in olive explants treated with auxin or with $A$. rhizogenes. The polyamine effect, however, was partially masked by rooting the explants by basal blanching. In shoots that were rooted by this method, the total endogenous PAs were present in low concentration at 2 days. Darkness probably promoted rapid PA degradation, and the catabolic products, e.g., hydrogen peroxide, might contribute to maintaining a low concentration of IAA during the induction phase. Putrescine treatment lowered the $\mathrm{pH}$ of the medium around

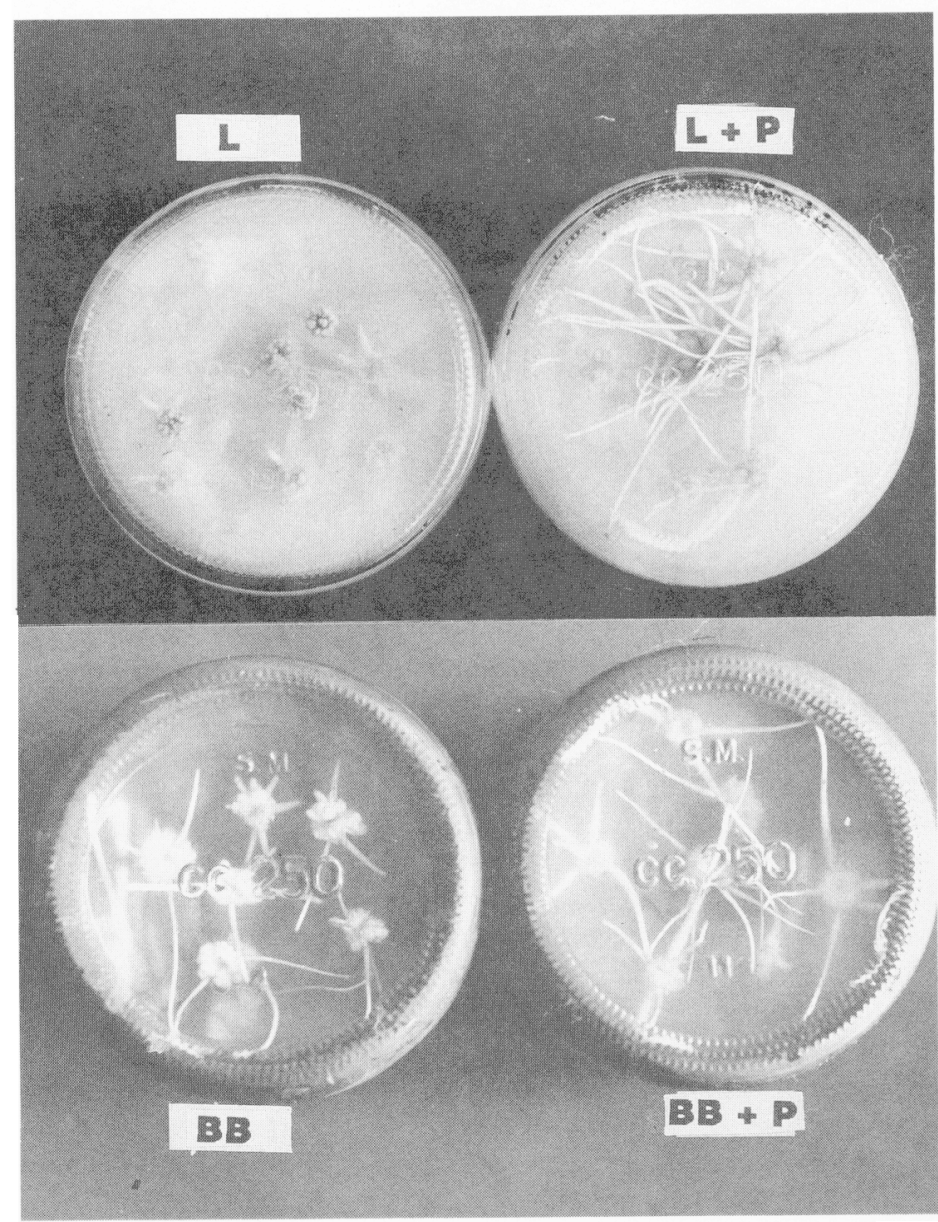

Fig. 3. Rooting of olive with $5 \mu \mathrm{M} \mathrm{NAA}$ under $60 \mu \mathrm{mol} \cdot \mathrm{m}^{-2} \cdot \mathrm{s}^{-1}$ irradiance at 36 days following treatments with: $\mathrm{L}$ (control; rooted in 16-h photoperiod); BB (rooted with basal blanching in 16-h photoperiod); $\pm 1 \mathrm{mM}$ putrescine $(\mathrm{P})$. Note the differences in root systems and the few rooted explants in the control.

Table 2. Total endogenous PAs in apical and basal explants rooted with $(+\mathrm{BB})$ or without $(-\mathrm{BB})$ basal blanching in a rooting medium containing $5 \mu \mathrm{M}$ NAA.

\begin{tabular}{crc}
\hline \hline & \multicolumn{2}{c}{ Davs from beginning of experiment } \\
Treatments & 2 & 5 \\
\hline & \multicolumn{3}{c}{$n \mathrm{nol}^{\prime} \cdot \mathrm{g}^{-1} \mathrm{FW} \pm S E$} \\
Apical - BB & $139 \pm 7.4$ & $70 \pm 1.4$ \\
+ BB & $93 \pm 2.8$ & $72 \pm 2.8$ \\
Basal - BB & $157 \pm 4.9$ & $78 \pm 2.1$ \\
+ BB & $84 \pm 0.7$ & $79 \pm 2.8$ \\
\hline
\end{tabular}

the explants, and this decrease could affect rooting. This fact makes it even more difficult to understand how PAs interfere with rooting, directly or indirectly even with their catabolic products. However, it is clear that their presence in the tissue is essential for rooting. The inhibition of polyamine synthesis by dymethylfluoronithine (DMFO) and dymethylfluoroarginine (DMFA) in Hedera helix L. (Geneve, 1987) and in cherry (Biondi et al., 1990) resulted in a low frequency of root primordia, supporting the hypothesis of Friedman et al. (1982) who suggested a possible regulatory role for PAs in combination with auxins in the early phase of adventitious root formation. Since Spd has been found to increase phenolic compounds in rose cell suspensions (Muhitch and Fletcher, 1986), it might contribute 
Table 3. Rooting of 'Moraiolo' olive explants with A. rhizogenes at 70 days in combination with growth regulators $(5 \mu \mathrm{M})$, 5-azacytidine $(28 \mu \mathrm{M})$ or putrescine $(1 \mathrm{mM})$.

\begin{tabular}{lccc}
\hline \hline \multirow{2}{*}{$\begin{array}{l}\text { Growth } \\
\text { regulator }\end{array}$} & \multicolumn{3}{c}{ Explants (no.) } \\
\cline { 2 - 4 } Control & $26 \mathrm{a}^{\mathbf{2}}$ & Unrooted & Total \\
\hline IAA & $29 \mathrm{a}$ & 32 & 58 \\
IBA & $30 \mathrm{a}$ & 31 & 60 \\
NAA & $26 \mathrm{a}$ & 30 & 60 \\
2,4-D & 0 & 34 & 60 \\
Zeatin & $11 \mathrm{~b}$ & 0 & 60 \\
GA & $3 \mathrm{~b}$ & 48 & 59 \\
5-azacytidine & $22 \mathrm{a}$ & 57 & 60 \\
Putrescine & $41 \mathrm{~b}$ & 38 & 60 \\
\hline
\end{tabular}

${ }^{2}$ Separation between untreated control and each treatment by $x^{2}$ test of homogeneity, $\boldsymbol{P}=0.05$.

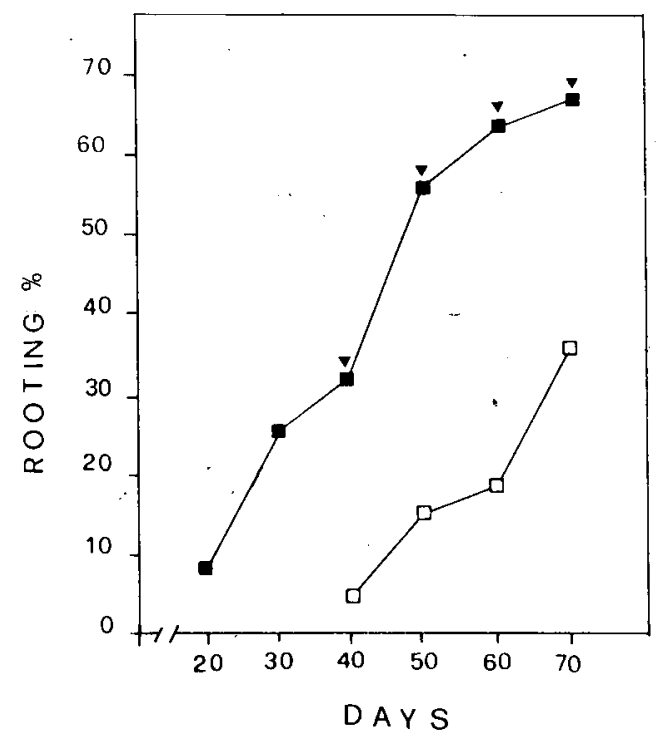

Fig. 4. Effect of $1 \mathrm{~mm}$ putrescine on rooting of 'Moraiolo' olive explants induced with $A$. rhizogenes ( $\boldsymbol{\square}$ ) and on untreated explants (Cl). Triangles placed on each point indicate difference by $t$ test with the corresponding mean of the control. Each datum is the mean of 60 explants.

to the formation of the auxin-phenolic complex putatively responsible for rooting (Hess, 1962). PAs similarly affected explants treated with A. rhizogenes and those treated with auxins. In fact, auxin and transformation with A. rhizogenes may be comparable, because both increase the endogenous auxin level. Putrescine, for the most part, did not affect the presence of opine in roots induced with $A$. rhizogenes even when they grew in medium containing 5-azacytidine, which has been found to activate T-DNA genes in plants transformed by A. tumefaciens (van Slogteren et al., 1984). However, the agropine gene is located on the TR-DNA (De Paolis et al., 1985) and is not required for root induction, as is TL-DNA; therefore, TR-DNA may not be integrated into the DNA plant cells. In fact, the absence of agropine has already been observed even in herbaceous plants (unpublished). As far as these experiments are concerned, rooting has never taken place in the species examined without the presence of auxin, indicating that differentiation was stimulated by the rol genes of the bacterial plasmid TL-DNA even though the roots were agropine negative.

Because PAs promote early rooting and increase the rooting percentage (hence eliminating the variable results often observed in our culture conditions), they could be of value even for ex vitro rooting of olive explants. Recent evidence in our laboratory showed that pretreatment of olive explants with putrescine extended their capacity for survival, and some of them rooted in agarized medium without a $\mathrm{C}$ source.

\section{Literature Cited}

Altman, A. R., R. Kaur-Sawhney, and A.W. Galston. 1977. Stabilization of oat leaf protoplants through polyamine mediated inhibition of senescence. Plant Physiol. 60:570-574.

Apelbaum, A., A.C. Burgeon, J.D. Anderson, and M. Lieberman. 1981. Polyamides inhibit biosynthesis of ethylene in higher plant tissue and fruit protoplasts. Plant Physiol 68:453-456.

Bagni, N., D. Serafini-Fracassini, and P. Torregiani. 1981. Polyamides and growth in higher plants, p. 377-388. In: C.M. Caldarera. V. Zappia, and V. Bachrach (eds.). Advances in polyamine research. vol. 3. Raven Press, New York.

Biondi, S., T. Diaz, I. Iglesias, G. Gamberini, and N. Bagni. 1990.. Polyamides and ethylene in relation to adventitious root formation in Prunus avium shoot cultures. Physiol. Plant. 78:474-483.

De Paolis, A., M.L. Mauro, M. Pomponi, M. Cardarelli, L. Spano, and P. Costantino. 1985. Localization of agropine synthesizing functions is in the TR-region of the root inducing plasmid of Agrobacterium rhizogenes 1855. Plasmid 13:1-7.

Friedman, R., A. Altman, and U. Bachrach. 1982. Polyamides and root formation in mung bean hypocotyl cuttings. I. Effect of exogenous compounds and changes in endogenous polyamine content. Plant Physiol. 70:844-848.

Friedman, R., A. Altman, and U. Bachrach. 1985. Polyamides and root formation in mung bean hypocotyl. Plant Physiol. 79:80-83.

Geneve, R. 1987. The involvement of polyamides in adventitious root initiation in de-blade petioles of Hedera helix cultured in vitro. Plant Physiol. (Supp.) 83:74. (Abstr.)

Hess, C.E. 1962. Characterization of the rooting co-factors extracted from Hedera helix L. and Hibiscus rosa sinensis L. Proc. 1st Intl. Hort. Congr. 382-388.

James, D.J. 1987. Cell and tissue culture technology for the genetic manipulation of temperature fruit trees. Biotechnol. and Genet. Eng. Rev. 5:33-79.

James, D.J. and I.J. Thurbon. 1979. Rapid in vitro rooting of the apple rootstock M 9. J. Hort. Sci. 54:309-311.

Jarvis, B. C., P.R.M. Shannon, and S. Yasmin. 1983. Involvement of polyamides with adventitious root development in stem cuttings of mung bean. Plant Ceil Physiol. 24:677-683.

Linsmaier, E.M. and F. Skoog. 1965. Organic growth factor requirements of tobacco tissue cultures. Physiol. Plant. 18:100-127.

Muhitch, M.J. and J.S. Fletcher. 1986. Influence of culture age and spermidine treatment on the accumulation of phenolic compounds in suspension cultures. Proc, VIth Intl. Congr. Plant Tissue and Cell Cult. Minneapolis. p. 348. (Abstr.)

Murashige, T. and F. Skoog. 1962. A revised medium for rapid growth and bio-assay with tobacco tissue culture. Physiol. Plant. 15:473497.

Patena, L., E.G. Sutter, and A.M. Dandekar. 1987. Root induction by Agrobacterium rhizogenes in a difficult-to-root woody species. Acts Hort. 227:324-329.

Rugini, E. 1986a. Almond, p. 574-611. In: D.A. Evans, W.R. Sharp, and P.V. Ammirato (eds.). Handbook of plant and cell culture. vol. 3. Macmillan, New York.

Rugini, E. 1986b. Olive (Olea europaea L.), p. 253-267. In: Y.P.S. Bajaj (cd.). Biotechnology in agriculture and forestry. vol. I. Trees. Springer-Verlag. Berlin.

Rugini, E., A. Jacoboni, and A. Bazzoffia. 1987. A simple in vitro method to avoid the initial dark period and to increase rooting in fruit trees. Acts Hort. 227:438-440.

Rugini, E., A. Pellegrineschi, M. Mencuccini, and D. Mariotti. 1991. Increase of rooting ability in the woody species kiwi (Actinidia de- 
liciosa A. Chev.) by transformation with Agrobacterium rhizogenes T-DNA rol genes. Plant Cell Rptr. 10:291-295.

Rugini, E. and X.S. Wang. 1986. Effect of polyamides, 5-azacytidine and growth regulators on rooting in vitro of fruit trees, treated and untreated with Agrobacterium rhizogenes. Proc. VIth Intl. Congr. Plant Tissue and Cell Cult., Minneapolis. p. 374. (Abstr.)

Smith, T.A. 1982. Polyamides as growth regulators. New Bul. 3:3-10.

Torregiani, P., M.M. Altamura, F. Capitani, G. Falasca, N. Bagni, and D. Serafini-Francassini. 1990. Inhibition of polyamine biosynthesis affects rhizogenesic reponse in tobacco thin cell layers. Proc.
VIth Intl. Congr. Plant Tissue and Cell Cult., Amsterdam. p. 480485.

van Slogteren, G. M. S., P.J.J. Hooykaas, and R.A. Schilpercort. 1984. Silent T-DNA genes in plant lines transformed by Agrobacterium tumefaciens are activated by grafting and by 5-azacytidine treatment. Plant Mol. Biol. 3:333-336.

White, F. F., G. Ghidossi, M.P. Gordon, and E.W. Nester. 1982. Tumor induction by Agrobacterium rhizogenes involves the transfer of plasmid DNA to the plant genome. Proc. Natl. Acad. Sci. (USA) 79:3193-3197. 